Article

\title{
The Solidification Behavior of AA2618 Aluminum Alloy and the Influence of Cooling Rate
}

\author{
Yulin Liu *, Ming Liu, Lei Luo, Jijie Wang and Chunzhong Liu
}

Liaoning Provincial Key Laboratory of Light Alloys and Processing Technology,

School of Materials Science and Engineering, Shenyang Aerospace University, 37 Daoyi Avenue S., Shenyang 110136, China; E-Mails: liuming.sau@gmail.com (M.L.); 1luo.sau@ gmail.com (L.L.); wangjijie@sau.edu.cn (J.W.); czliu@sau.edu.cn (C.L.)

* Author to whom correspondence should be addressed; E-Mail: ylliu@ sau.edu.cn;

Tel.: +86-133-5243-6226.

External Editor: Daolun Chen

Received: 24 September 2014; in revised form: 24 November 2014 / Accepted: 1 December 2014 / Published: 9 December 2014

\begin{abstract}
In AA2618 aluminum alloy, the iron- and nickel-rich intermetallics formed during solidification are of great effect on the mechanical properties of the alloy at both room temperature and elevated temperatures. However, the solidification behavior of the alloy and the formation mechanism of the intermetallics during solidification of the alloy are not clear. This research fills the gap and contributes to understanding the intermetallic of the alloy. The results showed that cooling rate was of great influence on the formation of the intermetallics. Under the condition of slow cooling, the as-cast microstructures of the alloy were complex with many coarse eutectic compounds including $\mathrm{Al}_{9} \mathrm{FeNi}, \mathrm{Al}_{7}(\mathrm{CuNi})_{5}, \mathrm{Si}$, $\mathrm{Al}_{2} \mathrm{Cu}$ and $\mathrm{Al}_{2} \mathrm{CuMg}$. The phase $\mathrm{Al}_{9} \mathrm{FeNi}$ was the dominant intermetallic compound, which precipitated at the earlier stage of the solidification by eutectic reaction $\mathrm{L} \rightarrow \alpha-\mathrm{Al}+$ $\mathrm{Al}{ }_{9} \mathrm{FeNi}$. Increasing the cooling rate would suppress the formation of the coarse eutectic intermetallics. Under the condition of near-rapid cooling, the as-cast microstructures of the alloy consisted of metastable intermetallics $\mathrm{Al}_{9} \mathrm{FeNi}$ and $\mathrm{Al}_{2} \mathrm{Cu}$; the equilibrium eutectic compounds were suppressed. This research concluded that intermetallics could be refined to a great extent by near-rapid cooling.
\end{abstract}


Keywords: aluminum alloy; AA2618 alloy; solidification behavior; near-rapid cooling; microstructure

\section{Introduction}

AA2618 alloy is an $\mathrm{Al}-\mathrm{Cu}-\mathrm{Mg}$ system alloy. With the addition of iron and nickel, it is suitable for applications at elevated temperatures. In most aluminum alloys, iron is considered a harmful impurity element, due to the formation of iron-rich intermetallics, which deteriorate the mechanical properties of alloys. However, in AA2618 aluminum alloy, iron is an important alloying element. It combines with nickel to form an insoluble iron- and nickel-rich intermetallic Al9FeNi. The size, morphology and distribution of the intermetallic in the alloy are of great influence on the mechanical properties of the alloy at both room temperature and elevated temperatures. The fine dispersoid particles play a positive role in improving the mechanical properties of the alloy at elevated temperatures by enhancing the microstructural stability of the alloy under thermal exposure [1,2]. However, as more iron and nickel are added to the alloy, more coarse iron- and nickel-rich intermetallics will form. The coarse iron- and nickel-rich intermetallics will act as stress risers and deteriorate the mechanical properties of the alloy. The extent of the deterioration depends on the size, shape and type of the intermetallics. The platelet-like iron-rich phases have usually been considered most detrimental to the mechanical properties of aluminum alloys due to their brittle features and the stress concentration caused by the needle-like morphology $[3,4]$. Therefore, efforts need to be dedicated to developing means of controlling the precipitation, growth and morphology of these iron-rich intermetallic phases during solidification. However, so far, the solidification behavior of AA2618 alloy has not been studied and the formation mechanism of its intermetallic compounds during solidification of the alloy is not clear.

Over the years, lots of research has been done to improve alloy AA2618. For example, Özbek studied heat treatment [5]; Cavaliere investigated hot and warm formation [6]; Sakthivel et al. studied reinforcing by $\mathrm{SiC}$ particles [7]; Yu et al. studied the effect of $\mathrm{Al3}(\mathrm{Sc}, \mathrm{Zr}$ ) phases [8]; Oguocha and Yannacopoulos investigated natural ageing behavior [9]; Wang et al. investigated the influence of deformation ageing treatment [10]; Novy et al. studied the microstructure change during aging [11]; Wang et al. investigated the microstructural evolution during creep [12]. All these researches on AA2618 aluminum alloy were about the microstructure and mechanical properties of the alloy. No research on the solidification behavior of AA2618 alloy and the formation and control of the intermetallics in the alloy was reported. A systematical study is necessary to resolve these questions.

As a first step, it is necessary to identify and understand the factors that will affect the solidification behavior and the as-cast microstructure of commercial alloys, especially, the formation and refinement of the iron-rich intermetallics. Recently, Liu et al. [4,13-15] made systematical investigations into the formation of the iron-rich intermetallics in $\mathrm{Al}-\mathrm{Cu} 206$ cast alloys. It was found that the formation of the iron-rich intermetallics was greatly affected by the alloy's chemical composition and its cooling conditions. AA2618 aluminum alloy is much more complicated than Al-Cu 206 alloy in terms of chemical composition. It can therefore be assumed that the solidification behavior of AA2618 alloy and the formation mechanism of the intermetallics in the alloy are also very complicated. 
Cooling rate is an important factor that would affect the solidification behavior of AA2618 alloy. It is hypothesized that under the condition of near-rapid cooling, the iron-rich intermetallic compounds formed during the solidification of the alloy could be greatly refined, minimizing the formation of coarse intermetallics. Should this hypothesis hold true, under near-rapid cooling, coarse intermetallics could be avoided when more alloying elements are added, which would improve the mechanical properties of the alloy. The cooling of the continuous strip casting process of aluminum alloy is a near-rapid cooling with a cooling rate of $10^{1}-10^{2} \mathrm{~K} \cdot \mathrm{s}^{-1}$. New material with high alloying elements contents could thus be developed and produced by the continuous strip casting process. Therefore, it is of theoretic and commercial interesting to conduct a research on the solidification behavior of AA2618 alloy under the condition of near-rapid cooling.

In this paper, the research was focused on the AA2618 alloy. Systematic research on the solidification behavior of the alloy, the formation of intermetallic A19FeNi and the influence of cooling rate will be helpful in refining the coarse intermetallics, in return, improving the mechanical properties of the alloy and optimizing the alloy composition.

\section{Experimental Procedures}

The material used in this study was a commercially produced thick plate, with a thickness of $20 \mathrm{~mm}$, in T6 temper. Its composition was analyzed by emission spectroscopy and the result was as follows, in wt\%: Al-2.21 Cu-1.29 Mg-1.10 Fe-1.03 Ni. Other elements included 0.17 Si, 0.03 Mn, 0.07 Zn and $0.09 \mathrm{Ti}$. The samples used for remelting were cut from the plate. The investigations were carried out by remelting different samples of the alloy and solidifying them at different cooling rates, and then analyzing the as-cast microstructures of each sample by metallographic examination with optical microscopy (OM) and electronic scanning microscopy (SEM) with Energy Dispersive X-ray Detector (EDX).

For each remelting-solidification test, approximately $80 \mathrm{~g}$ of material was remelted in an alumina ceramic crucible in an air furnace by heating the material to $1023 \mathrm{~K}\left(750{ }^{\circ} \mathrm{C}\right)$. The molten materials were kept for at least $30 \mathrm{~min}$ at the aforementioned temperature, in order to melt the material entirely and to homogenize the composition. The molten materials were then solidified under the different conditions summarized below in Table 1. In these experiments, the temperature was measured using a K-type thermocouple. The thermocouple was inserted along the centerline of the crucible or mold halfway into the melt. An evolution of temperature with time was recorded every 0.1 second. The average cooling rate of each sample was calculated by using the formula $\mathrm{d} T / \mathrm{d} t$ and was computed from the approximate straight-line portion of the cooling curve before the start of the solidification. Labsys Evo DSC (differential scanning calorimeter)-1600 from Setaram Instrumentation (Caluire, France) was used to analyze the heat flow during solidification.

Table 1. Summary of cooling conditions.

\begin{tabular}{ccc}
\hline Sample ID & Cooling condition & Cooling rate, $\mathbf{K}^{\mathbf{- 1}}$ \\
\hline FC (Furnace cooling) & Cooled in crucible in furnace & 0.037 \\
AC (Air cooling) & Cooled in crucible in air & 1.47 \\
IC (Iron mold cooling) & Cast in iron mold, casting size: $\Phi 25 \mathrm{~mm} \times 50 \mathrm{~mm}$ & 39.5 \\
\multirow{2}{*}{ WC (Water cold mold cooling } & Cast in a double-side water cooled iron mold, & 88.2 \\
\hline
\end{tabular}


The solidification sequences of the alloy were revealed by using an interrupted water quenching method-interrupting the solidification process and quenching the solidifying sample into water. This method was previously used by the present authors [16] and recently by Liu et al. [15] and has been proven to work. By quenching samples at different temperatures and by distinguishing the solidified structure and the water-quenched structure of the samples, the solidification process of the alloy could be revealed and the solidification sequence and microstructure could be determined. During solidification, the temperatures of the solidifying samples were in-line monitored. Once the pre-determined temperature (or time) was reached, the samples were quenched into water immediately. The transit time of the sample from furnace to water was less than one second.

Samples for metallographic investigations were cut from the solidified ingots in the vicinity of the thermocouple's tip, ground with $\mathrm{SiC}$ paper, polished with $3 \mu \mathrm{m}$ alumina water solution and finally polished using diamond solution. The samples were etched with a reagent $\left(25 \mathrm{vol} \% \mathrm{HNO}_{3}+2 \mathrm{vol} \% \mathrm{HF}\right.$ $+73 \mathrm{vol} \% \mathrm{H}_{2} \mathrm{O}$ ) and the microstructures of the samples were examined using an OLYMPUS GX71 optical microscope from Olympus Corporation (Shinjuku, Japan), A Zeiss scanning electron microscopy with energy dispersive X-ray (EDX) analyzer from Zeiss Group (Oberkochen, Germany) and a Shimdzu electronic probe microanalyzer (EPMA-1610) from Shimdzu Corporation (Kyoto, Japan) were employed to identify the intermetallic compounds.

\section{Results and Discussion}

\subsection{Microstructure Characteristics and Solidification Sequence of the Alloy under Slowing Cooling} (Samples FC and AC)

\subsubsection{Microstructure Characteristics}

The as-cast microstructures of Sample FC solidified at a cooling rate of $0.037 \mathrm{~K} \cdot \mathrm{s}^{-1}$ were revealed by $\mathrm{OM}$ and SEM, as shown in Figure 1. They consisted of primary $\alpha$-Al matrix and lots of intermetallic compounds. As marked in the backscatted electron images of the microstructures in Figure $1 \mathrm{~b}-\mathrm{d}$, at least five intermetallic phases could be identified: flower-like eutectic cluster in dark gray (marked as 1), flake/plate-like phase in light gray (marked as 2), blocky phase in light gray (marked as 3), black phase (marked as 4) and eutectic cellular in dark gray (marked as 5). The XRD (X-ray diffraction) patterns of the sample revealed the presence of $\mathrm{Al}_{9} \mathrm{FeNi}, \mathrm{Al}_{2} \mathrm{Cu}$ and $\mathrm{Al}_{2} \mathrm{CuMg}$, as shown in Figure 2.

A method for identifying intermetallics was to measure the chemical composition of the phases using EDX and EPMA. The results of the EDX examinations are summarized in Table 2. At least five spots were measured for each type of microstructures and no significant difference among the measurements was found. The EPMA results are also summarized in Table 2. It was discovered that the findings from the two instruments were quite close. The chemical compositions of type 1 and type 3 microstructures well matched the stoichiometric composition of $\mathrm{Al}_{9} \mathrm{FeNi}$ and $\mathrm{Al}_{2} \mathrm{Cu}$, respectively. Therefore, it was certain that the flower-like eutectic cluster (1) was $\mathrm{Al}$ 9FeNi and the blocky phase in light gray (3) was $\mathrm{Al}_{2} \mathrm{Cu}$. The flake/plate-like phase (2) contained $\mathrm{Al}, \mathrm{Cu}$ and $\mathrm{Ni}$ with an approximate ratio of $\mathrm{Al}_{7} \mathrm{Cu}_{3} \mathrm{Ni}_{2}$. According to the $\mathrm{Al}-\mathrm{Cu}-\mathrm{Ni}$ phase diagram [17], there were several types of closely-related structures of $\mathrm{Al}-\mathrm{Cu}-\mathrm{Ni}$ phases named as $\tau_{i}$. $\tau_{7}$ was a structure of $\mathrm{Al}_{7}(\mathrm{CuNi})_{5}$. The composition of the flake/plate-like phase (2) well matched this structure. Therefore, it was reasonable to define the flake/plate-like phase 
(2) as $\mathrm{Al} 7(\mathrm{CuNi}) 5$. The dark gray eutectic cellular (5) contained $\mathrm{Al}, \mathrm{Cu}$ and $\mathrm{Mg}$ with an approximate ratio of $\mathrm{Al}_{5} \mathrm{Cu}_{3} \mathrm{Mg}_{2}$. Since the eutectic compound was quite fine, the measurements might include some aluminum from the aluminum matrix, which caused the value of the measurements lower than their actual value in the phase. According to the $\mathrm{Al}-\mathrm{Cu}-\mathrm{Mg}$ phase diagram [18], at the aluminum corner, there were two eutectic compounds: $\mathrm{Al}_{2} \mathrm{Cu}$ (phase $\theta$ ) and $\mathrm{Al}_{2} \mathrm{CuMg}$ (phase $\mathrm{S}$ ). Although the composition of the dark gray eutectic cellular (5) deviated from $\mathrm{Al}_{2} \mathrm{CuMg}$, considering the fact that phase $\mathrm{Al}_{2} \mathrm{CuMg}$ was the only phase that contained both $\mathrm{Cu}$ and $\mathrm{Mg}$ as solutes, it was reasonable to define the dark gray eutectic cellular (5) as $\mathrm{Al}_{2} \mathrm{CuMg}$. The phase in black (4) contained mainly silicon. Although some aluminum was detected, it was reasonable to define this phase as silicon with other elements trapped within. The aluminum detected in the phase might have come from the aluminum matrix.

Figure 1. The as-cast microstructures of Sample FC (a) OM image; (b)-(d) SEM backscatted electron images.

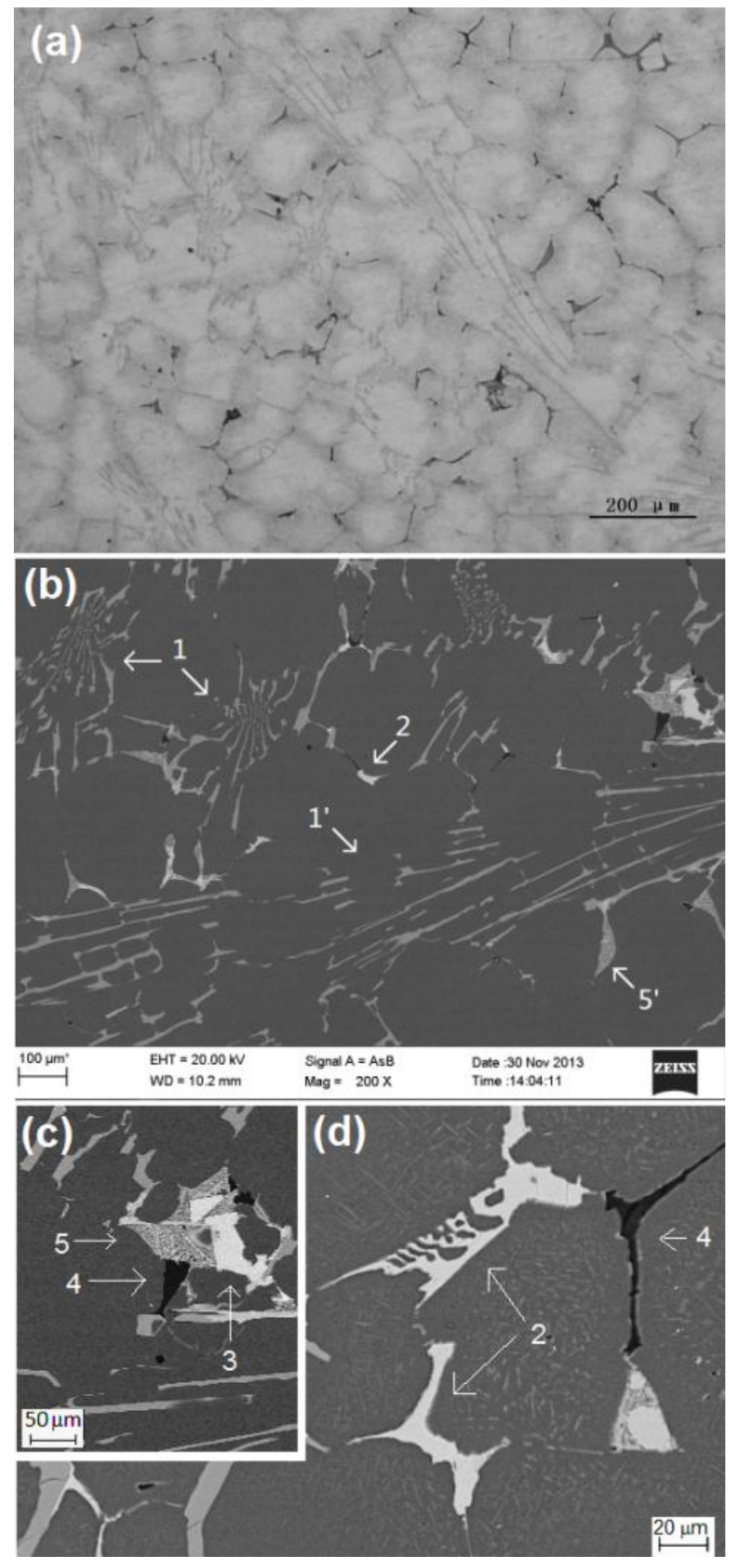


Figure 2. X-ray diffraction spectra of the Sample FC.

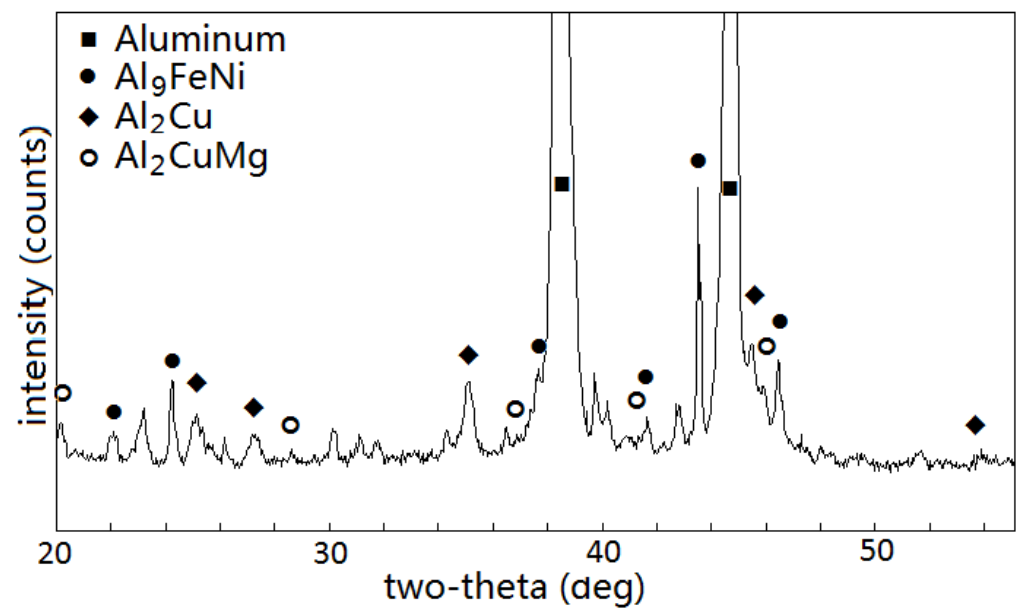

Table 2. Composition of intermetallic compounds in Sample FC measured by EDX and EPMA (at\%).

\begin{tabular}{|c|c|c|c|c|c|c|c|c|}
\hline $\begin{array}{c}\text { Phase \# as marked } \\
\text { in Figure } 1\end{array}$ & EDX/EPMA & Al & $\mathrm{Cu}$ & Mg & $\mathbf{F e}$ & $\mathbf{N i}$ & $\mathbf{S i}$ & $\begin{array}{c}\text { Suggested phase } \\
\text { formula }\end{array}$ \\
\hline \multirow[b]{2}{*}{1} & EDX & 81.35 & 0.51 & \multirow[b]{2}{*}{ - } & 8.84 & 9.30 & & \multirow{2}{*}{$\mathrm{Al}_{9} \mathrm{FeNi}$} \\
\hline & EPMA & 81.52 & 0.47 & & 8.06 & 9.74 & 0.22 & \\
\hline \multirow{2}{*}{2} & EDX & 59.19 & 21.86 & - & 0.27 & 18.68 & & \multirow{2}{*}{$\mathrm{Al}_{7}(\mathrm{CuNi})_{5}$} \\
\hline & EPMA & 59.47 & 22.49 & 0.02 & 0.11 & 17.89 & 0.02 & \\
\hline \multirow{2}{*}{3} & EDX & 66.63 & 32.27 & 1.10 & - & - & - & \multirow{2}{*}{$\mathrm{Al}_{2} \mathrm{Cu}$} \\
\hline & EPMA & 65.67 & 32.71 & 1.22 & 0.01 & 0.32 & 0.05 & \\
\hline \multirow{2}{*}{4} & EDX & 7.68 & - & - & 1.77 & & 90.55 & \multirow{2}{*}{ Silicon } \\
\hline & EPMA & 1.95 & 0.39 & 2.13 & 0.01 & 0.06 & 95.47 & \\
\hline \multirow{2}{*}{5} & EDX & 49.09 & 30.94 & 19.97 & - & - & - & \multirow{2}{*}{$\mathrm{Al}_{2} \mathrm{CuMg}$} \\
\hline & EPMA & 57.69 & 25.19 & 16.93 & 0.05 & 0.01 & 0.10 & \\
\hline
\end{tabular}

It was found by EDX and EPMA analyses that the composition of the radiated type structure, marked as 1 ' in Figure 1b, was almost the same as that of the flower-like structure, marked as 1 . Therefore, it was assumed that both of the structures were intermetallic phase $\mathrm{Al}_{9} \mathrm{FeNi}$. The $\mathrm{Al}_{7}(\mathrm{CuNi})_{5}$ phase also displayed complex morphologies, such as lamellar or Chinese script type structure, as shown in Figure 1d. Two types of eutectic cellular were observed, marked as 5 and 5 ' in Figure 1b,c, which usually lie beside the blocky $\mathrm{Al}_{2} \mathrm{Cu}$. The eutectic compound $\mathrm{Al}_{2} \mathrm{CuMg}$ formed a lamellar structure; Figure $3 \mathrm{a}$ shows a sample of this type of eutectic cellular. This type of eutectic cellular was more complex. It was a product of ternary eutectic reaction. The phase in light gray was $\mathrm{Al}_{2} \mathrm{Cu}$, while the phase in dark gray was $\mathrm{Al}_{2} \mathrm{CuMg}$. The presence of $\mathrm{Mg}$ made phase $\mathrm{Al}_{2} \mathrm{CuMg}$ display a little bit of darkness under the backscatted image. In addition, there was a plate-like (6) phase set in the eutectic cellular. EDX analysis indicated that it contained 70.21 at $\% \mathrm{Al}, 6.16$ at $\% \mathrm{Fe}, 3.58$ at $\% \mathrm{Ni}$ and 20.05 at\% $\mathrm{Cu}$. It might be phase $\mathrm{Al}_{7} \mathrm{Cu}_{2} \mathrm{Fe}$, as nickel was replaced by iron.

Figure 4 shows the as-cast microstructure of Sample AC solidified at a cooling rate of $1.47 \mathrm{~K} \cdot \mathrm{s}^{-1}$. Some changes in microstructure were observed comparing to Sample FC. The eutectic cluster of AlgFeNi mainly displayed flower-like patterns; no more radiated type structure was observed. The eutectic cellular increased in quantity. 
Figure 3. The morphologies of eutectic cellular: (a) eutectic $\alpha-\mathrm{Al}+\mathrm{Al}_{2} \mathrm{CuMg}$; (b) eutectic $\alpha-\mathrm{Al}+\mathrm{Al}_{2} \mathrm{Cu}+\mathrm{Al}_{2} \mathrm{CuMg}$.
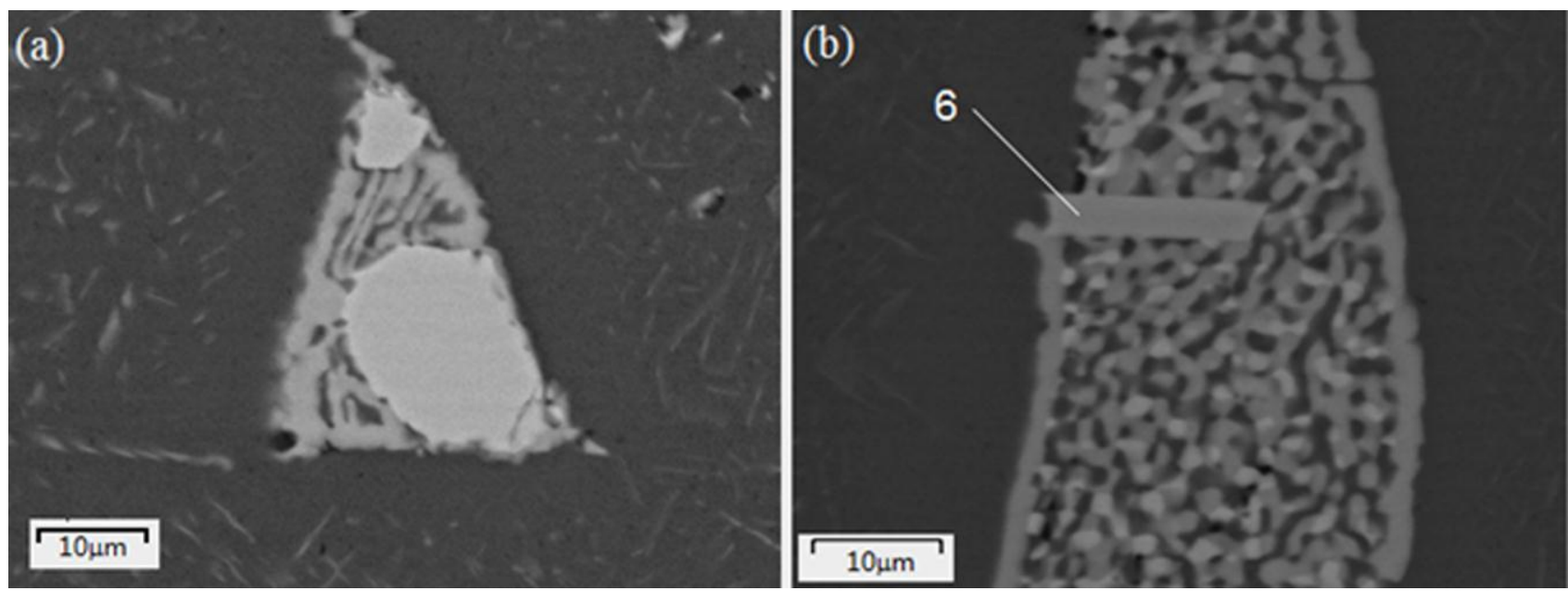

Figure 4. The as-cast microstructures of Sample AC.

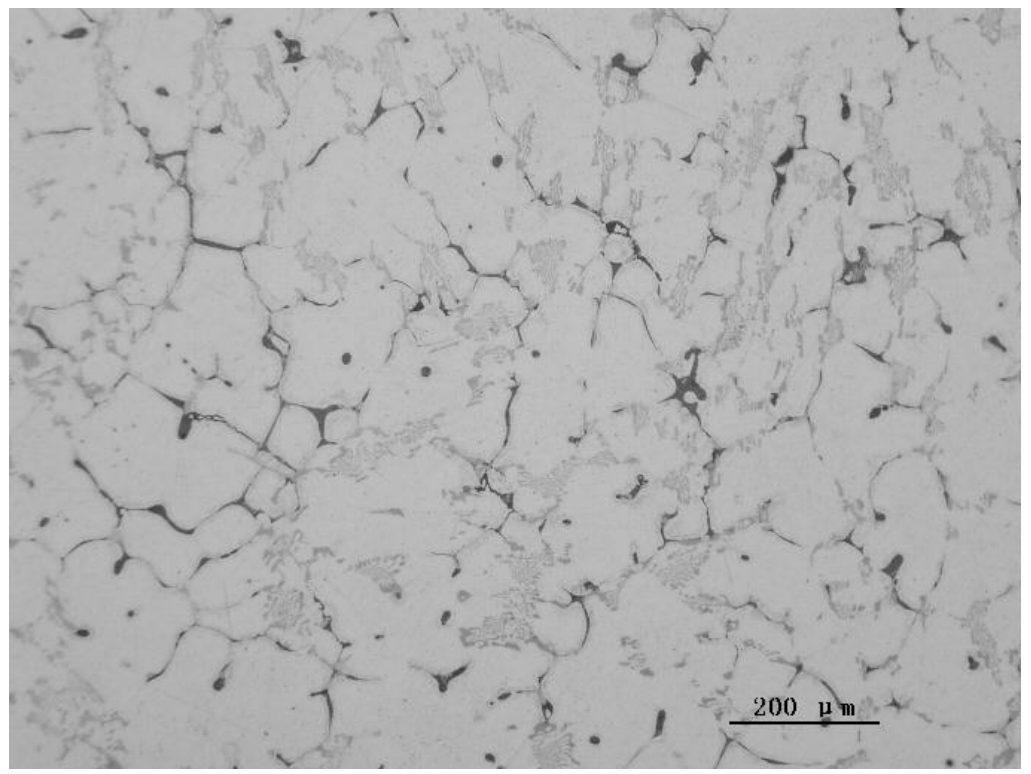

\subsubsection{Solidification Reaction and Sequence of the Alloy}

Figure 5 shows the thermal analysis curve and its first derivative of Sample FC. Several peaks were observed, which were denoted as (a), (b), (c) and (d), corresponding to thermal events that occurred during solidification of the alloy. Combining the thermal analysis and the as-cast microstructures observed, it could be deduced that the thermal event associated with peak (a) corresponded to the formation of primary $\alpha$-Al dendrites, which occurred at $912 \mathrm{~K}\left(639{ }^{\circ} \mathrm{C}\right)$; the other peaks were associated with the formations of the intermetallic phases.

There were some peak-like fluctuations between peaks (a) and (b). In order to determine whether these peak-like fluctuations were associated with precipitation of any intermetallic and to link the peaks to real processes and reactions that happened during solidification, a series of interrupted water-quenchings were performed during the solidification of the alloy in order to study the intermetallics that form at different times and temperatures. At the beginning of solidification, 
the decrease in the temperature of the molten alloy was very slow. The first group of five interrupted water-quenchings was conducted every four minutes from the start of thermal arrest. The second group of interrupted water-quenchings was conducted at different temperatures during cooling: 873, 848, 798, 773 and $763 \mathrm{~K}\left(600,575,525,500\right.$, and $\left.490{ }^{\circ} \mathrm{C}\right)$. It was found that no precipitation of intermetallic occurred in the first three quenched samples. In other words, no intermetallic precipitated from the liquid after $12 \mathrm{~min}$ of solidification. In the fourth quenched sample, quenched after 16 min of solidification (at temperature of approximately $903 \mathrm{~K}\left(630{ }^{\circ} \mathrm{C}\right)$ ), a large amount of long plate-like phases with a radiated type structure appeared, as shown in Figure 6a. The EDX analysis indicated that this phase possessed the chemical composition of $\mathrm{Al}{ }_{9} \mathrm{FeNi}$. These results confirmed that the peak-like fluctuations between peaks (a) and (b) were not associated with precipitation of any intermetallic. $\mathrm{Al}{ }_{9} \mathrm{FeNi}$ was the first intermetallic that precipitated from liquid, which corresponded to peak (b) at $631.5{ }^{\circ} \mathrm{C}$. The fraction of solid in this sample was about $28 \%$. In the fifth sample, quenched after $20 \mathrm{~min}$ of solidification (at around $901 \mathrm{~K}\left(628{ }^{\circ} \mathrm{C}\right)$ ), no new intermetallic was observed, but lots of $\mathrm{Al}{ }_{9} \mathrm{FeNi}$ with flower-like morphology displayed within triangle grain boundaries (Figure 6b). The fraction of solid in this sample was about $75 \%$.

Figure 5. Thermal analysis curve and its first derivation of Sample FC: (a) cooling rate and cooling time $v s$. temperature; (b) temperature and cooling rate $v s$. cooling time.

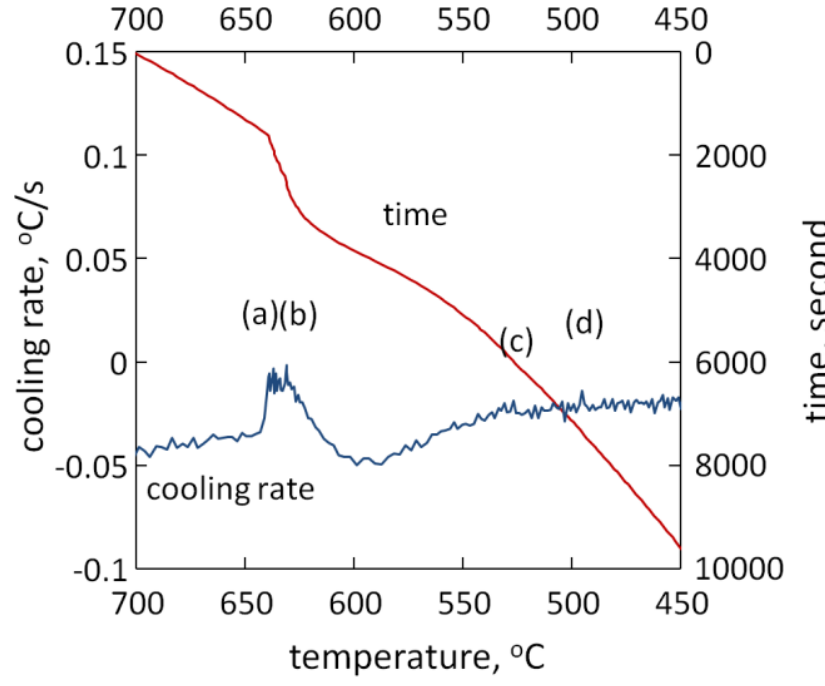

(a) time from start point of thermal arrest, second

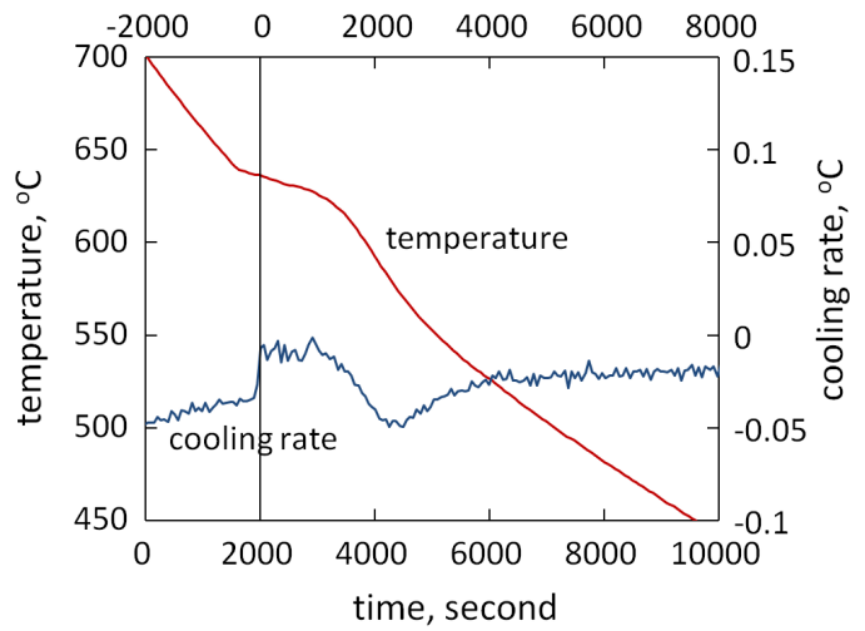

(b)

In the samples that were quenched at 873 and $848 \mathrm{~K}\left(600\right.$ and $\left.575^{\circ} \mathrm{C}\right)$, the solid fraction increased to about $86 \%$ and $93 \%$, respectively, but no new intermetallic was observed. Figure $6 \mathrm{c}$ shows that a new intermetallic, $\mathrm{Al} 7(\mathrm{CuNi})_{5}$, was found in the sample quenched at $798 \mathrm{~K}\left(525{ }^{\circ} \mathrm{C}\right)$, which was slightly lower than the temperature of peak (c). In this sample, the solid fraction was about $96 \%$.

In the sample that was quenched at $773 \mathrm{~K}\left(500{ }^{\circ} \mathrm{C}\right)$, the alloy had not yet fully solidified, some water-quenched structures could still be found, as shown in Figure 6d); the fraction of remaining liquid was about $1 \%$. Fully solidified structure was observed in the sample quenched at $763 \mathrm{~K}$ $\left(490{ }^{\circ} \mathrm{C}\right.$ ), see Figure 6e. It was certain that the solidification process terminated between $773 \mathrm{~K}$ $\left(500{ }^{\circ} \mathrm{C}\right)$ and $763 \mathrm{~K}\left(490{ }^{\circ} \mathrm{C}\right)$. Figure 7 shows the solidification fractions vs. temperature. 
Figure 6. The microstructures after interrupted quenching at different temperatures: (a) $630{ }^{\circ} \mathrm{C}(16 \mathrm{~min})$; (b) $628^{\circ} \mathrm{C}(20 \mathrm{~min})$; (c) $525^{\circ} \mathrm{C}$; (d) $495{ }^{\circ} \mathrm{C}$ and (e) $485^{\circ} \mathrm{C}$.
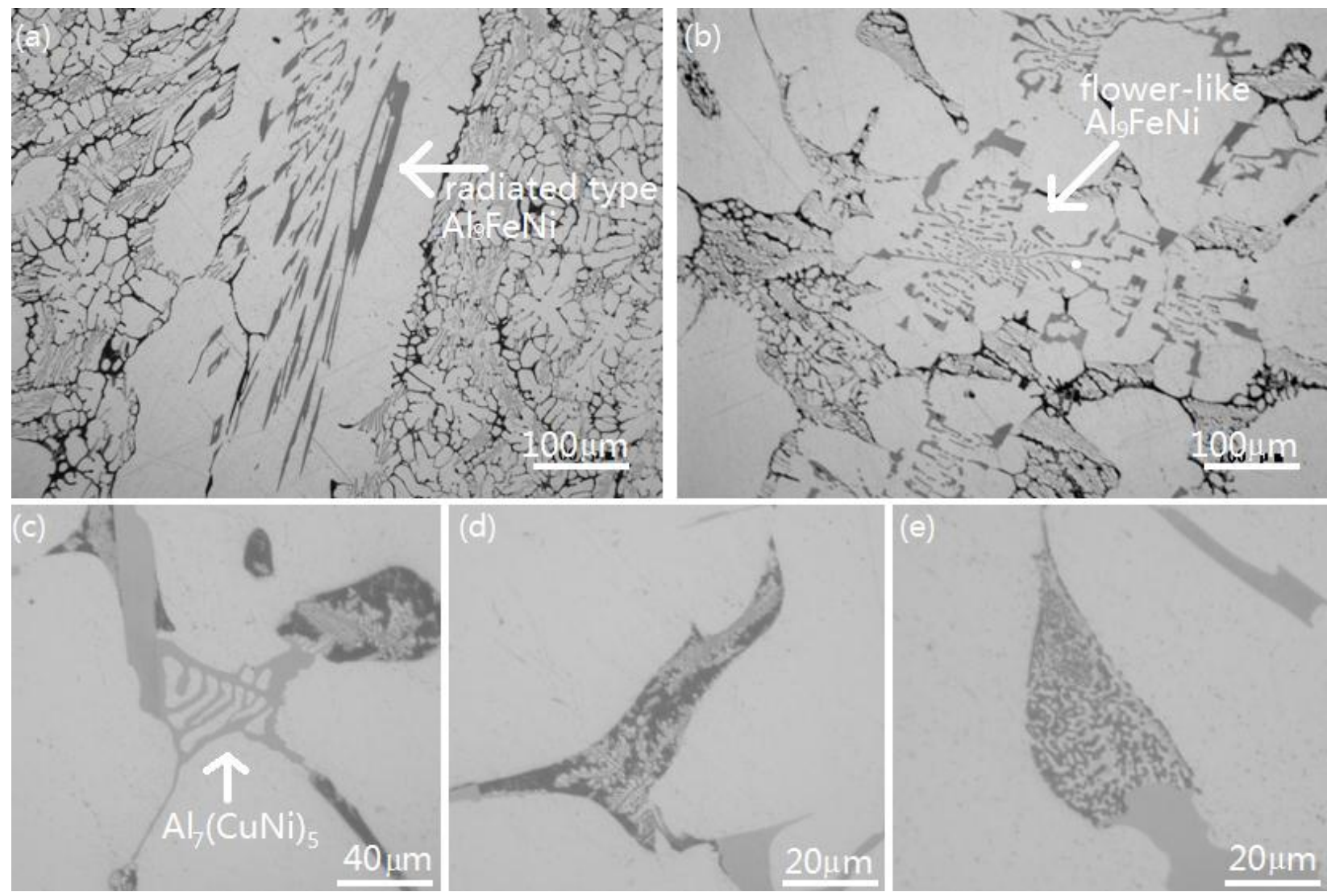

Figure 7. Solidification fraction vs. temperature.

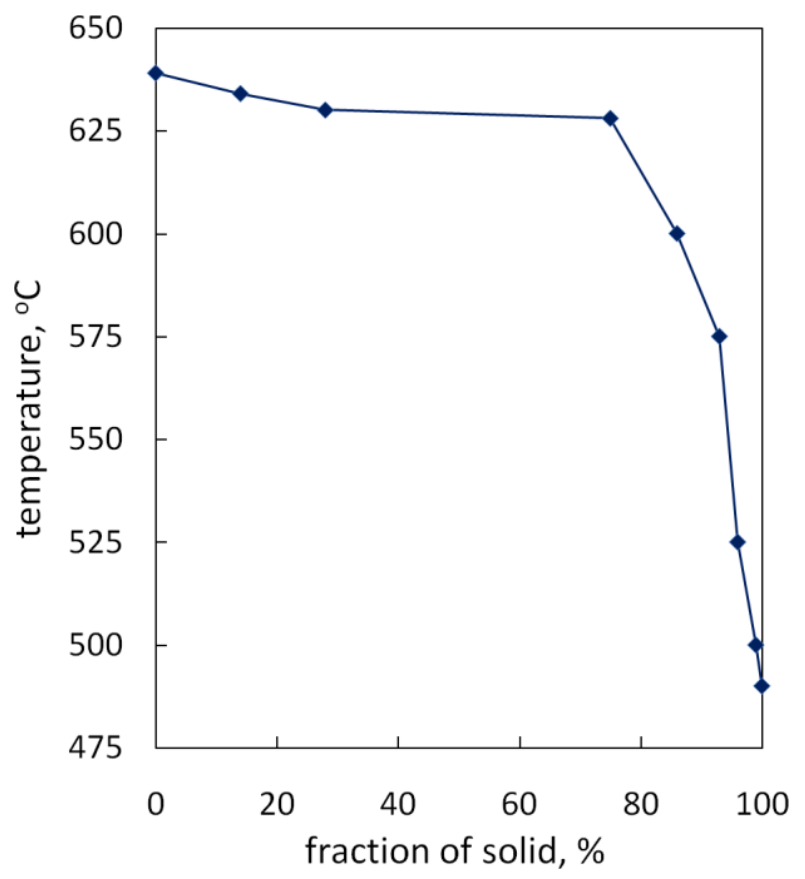

Setaram Labsys Evo DSC-1600 differential scanning calorimeter was used to analyze the heat flow during solidification. $10.0 \mathrm{mg}$ material was heated to $710{ }^{\circ} \mathrm{C}$, and then cooled to $430{ }^{\circ} \mathrm{C}$ at a cooling rate of $2 \mathrm{~K} \cdot \mathrm{s}^{-1}$, which was close to the cooling rate of Sample FC. The DSC curve is shown in 
Figure 8. Two reaction peaks were observed on the DSC curve at 638 and $631{ }^{\circ} \mathrm{C}$. Upon cooling from $710{ }^{\circ} \mathrm{C}$, the alloy began to solidify at $638^{\circ} \mathrm{C}$. A second solidification reaction was observed at $631{ }^{\circ} \mathrm{C}$, which must have corresponded to the formation of intermetallic $\mathrm{Al} 9 \mathrm{FeNi}$. Since the sample for DSC analysis was very small $(10.0 \mathrm{mg})$ and the quantities of other intermetallics $\left(\mathrm{Al}_{7}(\mathrm{CuNi})_{5}, \mathrm{Al}_{2} \mathrm{Cu}\right.$, $\mathrm{Al}_{2} \mathrm{CuMg}$ ) formed under slow cooling were also small, the reaction peaks for those intermetallics could be too small to be detected.

From the thermal analysis curve, phase diagrams of $\mathrm{Al}-\mathrm{Fe}-\mathrm{Ni}$ [19], $\mathrm{Al}-\mathrm{Cu}-\mathrm{Ni}$ [17] and $\mathrm{Al}-\mathrm{Cu}-\mathrm{Mg}$ [18], the as-cast microstructures observed, and the findings from the interrupted quenching tests, it could be assumed that $\alpha-\mathrm{Al}+\mathrm{Si}$ eutectic, $\alpha-\mathrm{Al}+\mathrm{Al}_{2} \mathrm{Cu}$ eutectic and/or $\alpha-\mathrm{Al}+\mathrm{Al}_{2} \mathrm{Cu}+\mathrm{Al}_{2} \mathrm{CuMg}$ ternary eutectic formed in the final solidification zones. All possible solidification reactions and sequences were summarized in Table 3 . The formation temperatures of primary $\alpha-\mathrm{Al}$ and intermetallic $\mathrm{Al}$ (9FeNi could be well defined. Reasonable ranges could be given to the formation temperatures of other intermetallics.

Table 3. Solidification sequence of Sample FC.

\begin{tabular}{cccc}
\hline Peak & Solidification & Reaction & Temperature, K $\left({ }^{\circ} \mathbf{C}\right)$ \\
\hline (a) & Primary $\alpha-\mathrm{Al}$ dendrite network & Primary & $912-911(639-638)$ \\
(b) & $\mathrm{L} \rightarrow \alpha-\mathrm{Al}+\mathrm{Al}_{9} \mathrm{FeNi}$ & eutectic & $905-904(632-631)$ \\
(c) & $\mathrm{L} \rightarrow \alpha-\mathrm{Al}+\mathrm{Al}_{7}(\mathrm{CuNi})_{5}$ & eutectic & Around $800(527)$ \\
(d) & $\mathrm{L} \rightarrow \alpha-\mathrm{Al}+\mathrm{Si}$ & eutectic & $773-763(500-490)$ \\
$(\mathrm{d})$ & $\mathrm{L} \rightarrow \alpha-\mathrm{Al}+\mathrm{Al}_{2} \mathrm{Cu}$ & eutectic & $773-763(500-490)$ \\
(d) & $\mathrm{L} \rightarrow \alpha-\mathrm{Al}+\mathrm{Al}_{2} \mathrm{Cu}+\mathrm{Al}_{2} \mathrm{CuMg}$ & eutectic & $773-763(500-490)$ \\
\hline
\end{tabular}

Figure 8. DSC curve of the alloy.

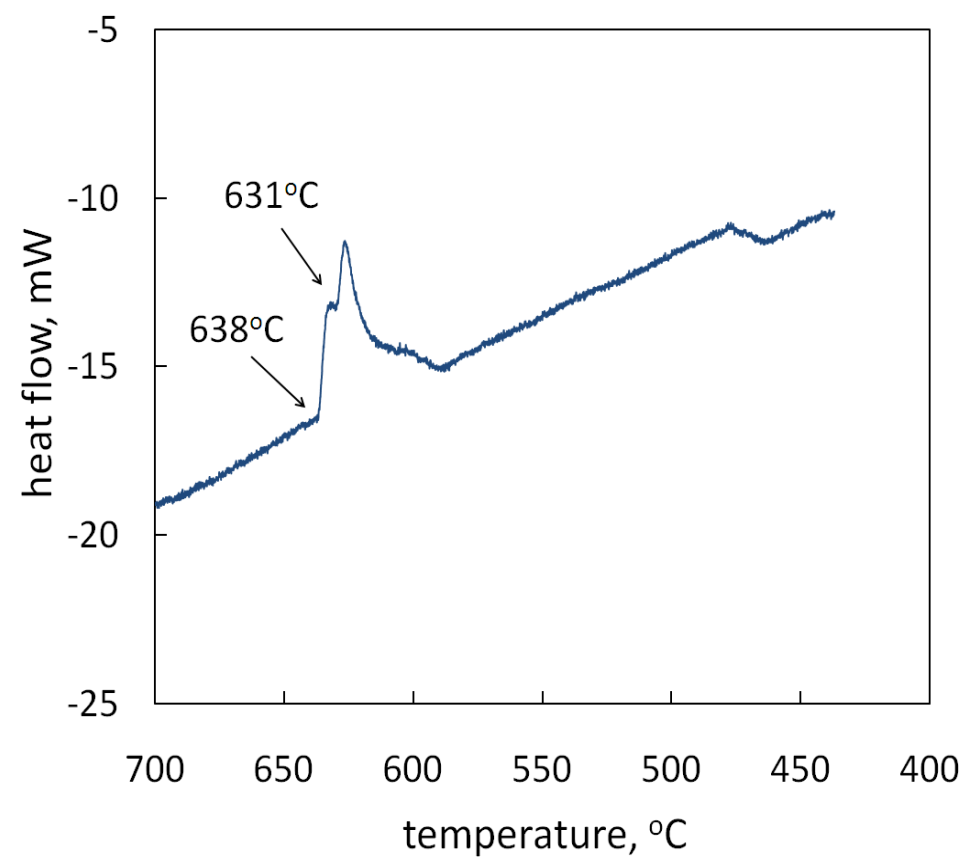

From Figure 1 it could be seen that under the condition of slow cooling, phase $\mathrm{Al}{ }_{9} \mathrm{FeNi}$ was the predominant intermetallic in the as-cast microstructure in the studied alloy with $1.10 \%$ iron and $1.03 \%$ nickel. According to the Al-Fe-Ni phase diagram [19], shown in Figure 9, alloy Al-1.10Fe-1.03Ni would start to solidify with the precipitation of primary $\mathrm{Al} 9 \mathrm{FeNi}$ at about $938 \mathrm{~K}\left(665^{\circ} \mathrm{C}\right)$; then eutectic 
reaction $\mathrm{L} \rightarrow \mathrm{Fe}_{4} \mathrm{Al}_{13}+\mathrm{Al}_{9} \mathrm{FeNi}$ follows; finally peritectic reaction $\mathrm{L}+\mathrm{Fe}_{4} \mathrm{Al}_{13} \rightarrow \alpha$ - $\mathrm{Al}+\mathrm{Al} 9 \mathrm{FeNi}$ would occur at around $923 \mathrm{~K}\left(650^{\circ} \mathrm{C}\right)$. But this investigation on the solidification of the studied alloy indicated that the solidification temperature of the alloy was about $912 \mathrm{~K}\left(639^{\circ} \mathrm{C}\right)$ and the primary phase was $\alpha$-Al, instead of $\mathrm{Al}{ }_{9} \mathrm{FeNi}$. The actual solidification temperature is about $26 \mathrm{~K}\left(26^{\circ} \mathrm{C}\right)$ lower than that predicted by the $\mathrm{Al}-\mathrm{Fe}-\mathrm{Ni}$ phase diagram. Therefore, it could be concluded that the presence of copper and magnesium affected the solidification behavior of the Al-Fe-Ni system.

With the decrease in temperature of the molten aluminum to its solidification temperature, the primary $\alpha$-Al precipitated and formed the matrix of the material. In aluminum alloy, the solute iron possessed strong tendency of segregation and formed iron containing intermetallic compounds [20]. During solidification, solutes segregated to the interface front of solidification. The solutes iron and nickel reached the eutectic composition first in the interface front, and then eutectic reaction $\mathrm{L} \rightarrow \alpha-\mathrm{Al}+\mathrm{Al}_{9} \mathrm{FeNi}$ occurred. The interrupted water-quenching test indicated that the solid fraction in the quenched sample that took place 16 min after solidification was about $28 \%$. The eutectic reaction $\mathrm{L} \rightarrow \alpha-\mathrm{Al}+\mathrm{Al}{ }_{9} \mathrm{FeNi}$ took place at the early stage of the solidification process. Many growing grains did not meet each other; the liquid had not yet been separated by the growing gains. In those areas, there was enough room for the $\mathrm{Al}{ }_{9} \mathrm{FeNi}$ phase to grow into a radiated type structure. With the decrease in temperature, the solid fraction increased. More and more growing grains met each other; the liquid had been gradually separated by the growing grains and limited to the triangle grain boundaries. This was confirmed by the fifth interrupted water-quenching test $\left(20 \mathrm{~min}\right.$ after solidification at about $901 \mathrm{~K}\left(628^{\circ} \mathrm{C}\right)$ ). The $\mathrm{Al} 9 \mathrm{FeNi}$ formed at lower temperature would not have enough room to extend; so it grew as flower-like morphology within the triangle grain boundaries.

Figure 9. Al-Fe-Ni partial liquidus projection of Al-corner [19].

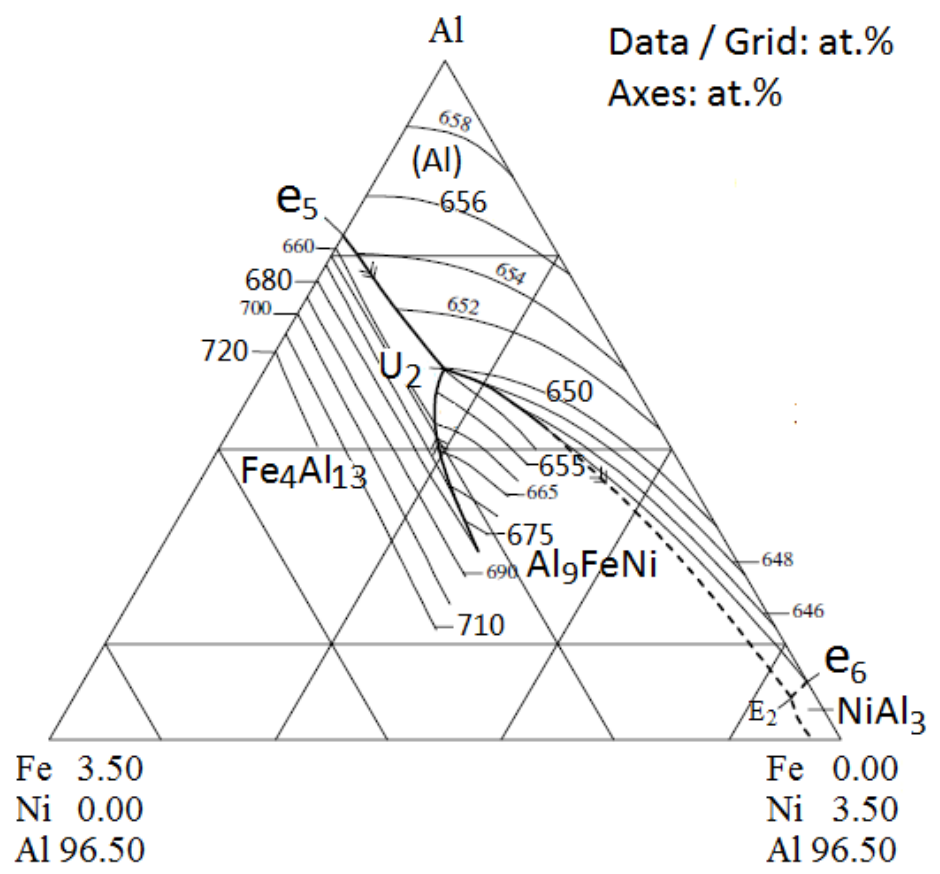

With the solidification continuing, the remaining liquid at inter-grain and interdendritic regions was enriched with solutes; the eutectic reaction $\mathrm{L} \rightarrow \alpha-\mathrm{Al}+\mathrm{Al}_{7} \mathrm{Cu}_{4} \mathrm{Ni}$ followed. According to the $\mathrm{Al}-\mathrm{Cu}-\mathrm{Ni}$ diagram [17], the eutectic reaction $\mathrm{L} \rightarrow \alpha-\mathrm{Al}+\mathrm{Al}_{7} \mathrm{Cu} 4 \mathrm{Ni}$ occurred between 858 and $808 \mathrm{~K}\left(585-535{ }^{\circ} \mathrm{C}\right)$. 
The precipitation temperature of $\mathrm{Al}_{7}(\mathrm{CuNi})_{5}$ in this study was close to this range. Then, the eutectic reaction $\mathrm{L} \rightarrow \alpha-\mathrm{Al}+\mathrm{Si}$ took place. In the final solidification zone, the liquid was enriched with copper and magnesium and formed two intermetallic compounds $\mathrm{Al}_{2} \mathrm{Cu}$ and $\mathrm{Al}_{2} \mathrm{CuMg}$.

There were two kinds of $\mathrm{Al}_{2} \mathrm{Cu}$. One formed in the binary eutectic reaction $\mathrm{L} \rightarrow \alpha-\mathrm{Al}+\mathrm{Al}_{2} \mathrm{Cu}$. When the eutectic composition was reached at the interface front, the eutectic reaction occurred and eutectic compounds formed and appeared as blocks. The formation of $\mathrm{Al}_{2} \mathrm{Cu}$ reduced the concentration of copper in the remaining liquid, which created the binary eutectic reaction $\mathrm{L} \rightarrow \alpha-\mathrm{Al}+\mathrm{Al}_{2} \mathrm{CuMg}$. The intermetallic compound $\mathrm{Al}_{2} \mathrm{CuMg}$ formed lamellar or Chinese script morphologies, which were the typical eutectic structure. The other kind of $\mathrm{Al}_{2} \mathrm{Cu}$ formed in the ternary eutectic reaction $\mathrm{L} \rightarrow \alpha-\mathrm{Al}+\mathrm{Al}_{2} \mathrm{Cu}+\mathrm{Al}_{2} \mathrm{CuMg}$. Both $\mathrm{Al}_{2} \mathrm{Cu}$ and $\mathrm{Al}_{2} \mathrm{CuMg}$ appeared as blocky particles. The solidification process ended with the ternary eutectic reaction.

When the cooling rate was increased to $1.47 \mathrm{~K} \cdot \mathrm{s}^{-1}$ with Sample AC, the solidification rate greatly increased. Once the solidification started with the formation of the primary $\alpha$-Al, the liquid was quickly separated by the growing $\alpha-A l$. Therefore, in this sample, no radiated type structure could form; the eutectic reaction $\mathrm{L} \rightarrow \alpha-\mathrm{Al}+\mathrm{Al}{ }_{9} \mathrm{FeNi}$ was limited in the regions isolated by the growing $\alpha-\mathrm{Al}$. Only flower-like structures were observed in the triangle grain boundaries.

\subsection{The As-Microstructure Characteristics of the Alloy under Near-Rapid Cooling}

When the alloy solidified at a higher cooling rate, significant change took place in the as-cast microstructure. Figure 10 shows the as-cast microstructure of Sample IC, solidified at a cooling rate of $39.5 \mathrm{~K} \cdot \mathrm{s}^{-1}$. No flower-like eutectic cluster and fine eutectic cellular were observed. Only some eutectic structure formed at grain boundaries. At high magnification, it was observed that the eutectic structure consisted of two intermetallic compounds. The EDX and EPMA analyses, as shown in Table 4, indicated that the white phase contained mainly aluminum and copper, while the gray phase contained mainly aluminum, iron and nickel. But the contents of copper in the white phase and the iron and nickel in the gray phase were relatively low; much lower than the stoichiometric compositions of the equilibrium phases. It was assumed that they were metastable states. The white phase could be the metastable state of $\mathrm{Al}_{2} \mathrm{Cu}$, while the gray phase could be the metastable state of $\mathrm{Al}_{9} \mathrm{FeNi}$. The eutectic structures were the product of ternary eutectic reaction of $\mathrm{L} \rightarrow \alpha$-Al + metastable $\mathrm{Al}_{2} \mathrm{Cu}+$ metastable $\mathrm{Al}_{9} \mathrm{FeNi}$. However, further detailed research is needed to study the crystal structures and properties of those phases formed under the condition of near-rapid solidification with lower chemical compositions.

Increasing cooling rate from 39.5 to $88.2 \mathrm{~K} \cdot \mathrm{s}^{-1}$ did not change the properties of the as-cast microstructure of the alloy. Figure 11 shows the as-cast microstructure of Sample WC solidified at a cooling rate of $88.2 \mathrm{~K} \cdot \mathrm{s}^{-1}$. It was observed that the morphologies and the distribution of the intermetallic compounds were almost the same as those observed in the previous sample; but the sizes of the grains and the compounds were further reduced and the amount of white phases increased. The eutectic structures were also composed of two intermetallic compounds and they were also metastable states. The EDX and EPMA analyses, as listed in Table 5, indicated that the compositions of the phases were close to those observed in Sample IC. Therefore, the white phase could also be the metastable state of $\mathrm{Al}_{2} \mathrm{Cu}$, while the gray phase could also be the metastable state of $\mathrm{Al}_{9} \mathrm{FeNi}$. 
Figure 10. As-cast microstructures of the Sample IC: (a) OM image; (b) SEM backscatted electron image.
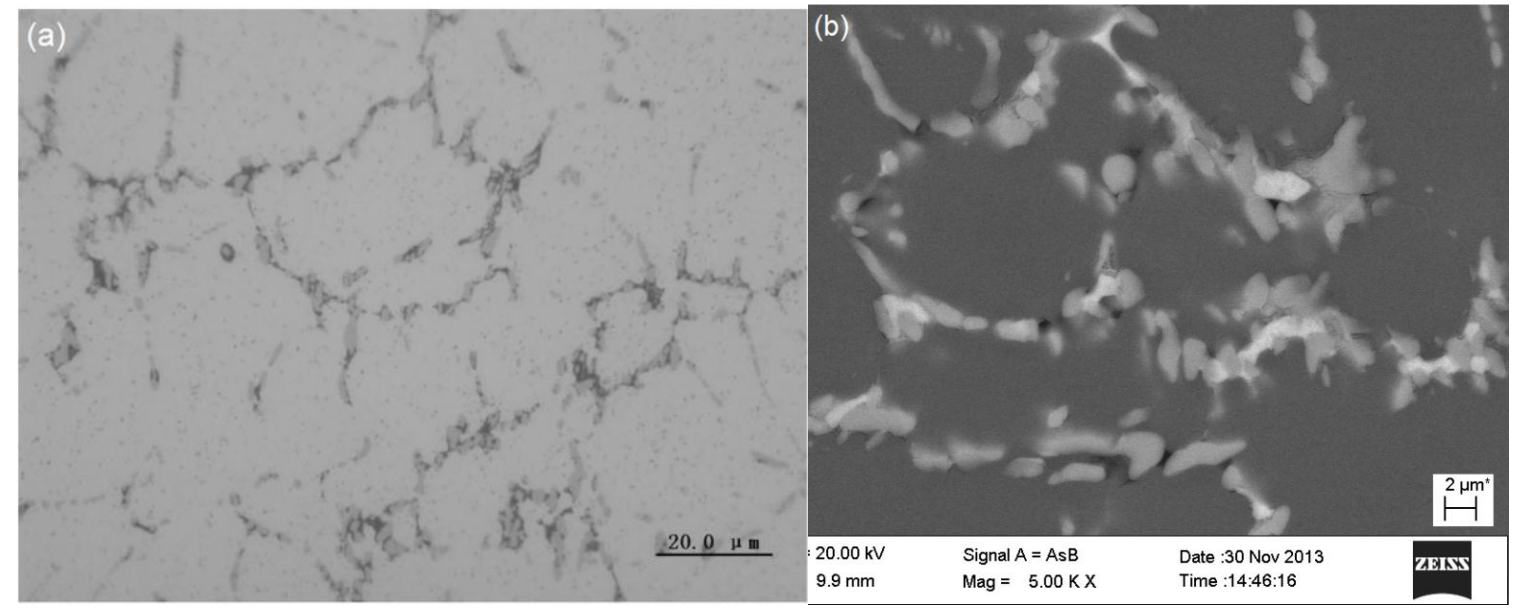

Table 4. The compositions of intermetallic compounds in Sample IC measured by EDX and EPMA (at\%).

\begin{tabular}{cccccccc}
\hline Phase & EDX/EPMA & $\mathbf{A l}$ & $\mathbf{C u}$ & $\mathbf{M g}$ & $\mathbf{F e}$ & $\mathbf{N i}$ & Suggested Phase formula \\
\hline \multirow{2}{*}{ White } & EDX & 78.76 & 18.04 & 1.92 & 0.53 & 0.76 & \multirow{2}{*}{ Metastable $\mathrm{Al}_{2} \mathrm{Cu}$} \\
\cline { 2 - 7 } & EPMA & 75.44 & 16.40 & 1.28 & 2.83 & 3.85 & \\
\hline \multirow{2}{*}{ Gray } & EDX & 85.37 & 2.23 & 1.43 & 5.4 & 5.49 & \multirow{2}{*}{ Metastable $\mathrm{Al}_{9} \mathrm{FeNi}$} \\
\cline { 2 - 6 } & EPMA & 79.67 & 3.92 & 3.27 & 6.04 & 6.70 & \\
\hline
\end{tabular}

Figure 11. As-cast microstructures of the Sample WC: (a) OM image; (b) SEM backscatted electron image.

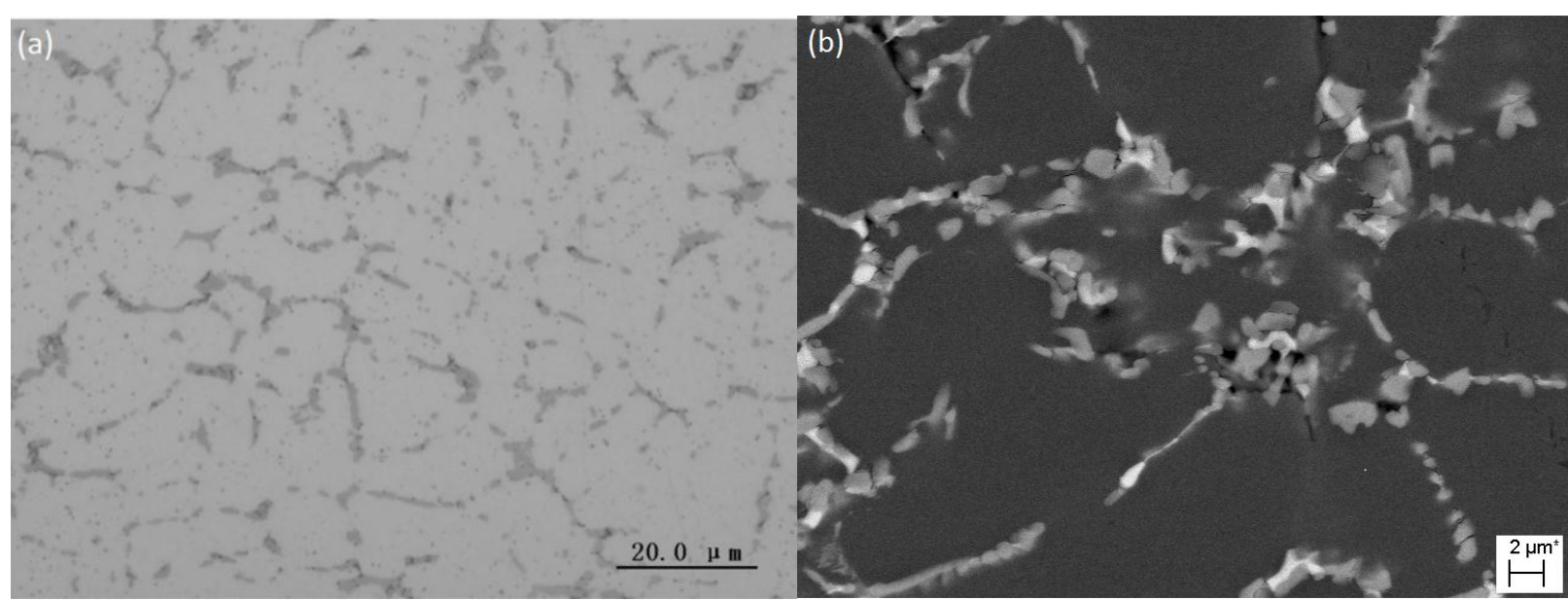

Table 5. The compositions of intermetallic compounds in Sample WC measured by EDX and EPMA (at\%).

\begin{tabular}{cccccccc}
\hline Phase & EDX/EPMA & $\mathbf{A l}$ & $\mathbf{C u}$ & $\mathbf{M g}$ & $\mathbf{F e}$ & $\mathbf{N i}$ & Suggested Phase formula \\
\hline \multirow{2}{*}{ White } & EDX & 77.81 & 18.18 & 2.03 & 0.77 & 1.20 & \multirow{2}{*}{ Metastable $\mathrm{Al}_{2} \mathrm{Cu}$} \\
\cline { 2 - 7 } & EPMA & 66.91 & 24.38 & 1.03 & 2.83 & 4.51 & \\
\hline \multirow{2}{*}{ Gray } & EDX & 85.02 & 3.55 & 1.18 & 5.11 & 5.13 & \multirow{2}{*}{ Metastable $\mathrm{Al}_{9} \mathrm{FeNi}$} \\
\cline { 2 - 6 } & EPMA & 84.65 & 1.13 & 1.09 & 6.50 & 6.32 & \\
\hline
\end{tabular}


The cooling rate had great influence on the as-cast microstructure of the alloy. It was interesting and necessary to analyze the solidification process of the alloy.

In Sample IC, which was solidified at a cooling rate of $39.5 \mathrm{~K} \cdot \mathrm{s}^{-1}$, the as-cast microstructures were quite simple with only primary $\alpha$-Al plus metastable intermetallics $\mathrm{Al}$ gFeNi and $\mathrm{Al}_{2} \mathrm{Cu}$, which could be attributed to the high cooling rate. Under the condition of near-rapid solidification, the solute segregation was limited by two factors. One was that the grain size and arm space of the dendrite was reduced, which gave rise to the increase in the number of final solidification zones in the grain boundaries and inter-dendrite regions. In return, the concentration of solutes in the final solidification zones was thinned. The other factor was that the fast solidification speed limited the enrichment of solutes in the final solidification zone, since the rejection of solute into the interface front was limited. Therefore, when the final solidification temperature was reached, the concentration of the solutes was not able to reach the equilibrium composition of eutectic compounds, resulting in products from the eutectic reaction being metastable phases.

Cooling rate is of great influence on the solidification and segregation behavior of the alloy. Zhang and $\mathrm{Gao}$ [21] conducted an investigation on the microstructure of rapid solidified $\mathrm{Al}-4 \mathrm{Cu}-\mathrm{Mg}-3 \mathrm{Fe}-4 \mathrm{Ni}$ alloy and found that under the condition of rapid solidification, only intermetallic $\mathrm{Al}_{3} \mathrm{Ni}$ was observed in the as-spun sample; almost all the solute atoms were trapped in the $\alpha$-Al matrix. Therefore, the formation of coarse intermetallics could be suppressed by fast cooling. This study concluded that increasing cooling rate from slow cooling to near-rapid cooling, the as-cast microstructures changed from complex multi eutectic compounds to simple metastable ternary eutectic compounds.

The as-cast microstructures can be simplified by near-rapid solidification. The coarse intermetallics formed under slow cooling can be avoided by increasing the cooling rate. In other words, the intermetallics can be refined to a great extent by near-rapid cooling. This is very interesting to the development of this kind of alloy. It is assumed that under near-rapid solidification, such as in the process of continuous strip casting, the alloying elements can be increased to a high level without forming coarse intermetallic compounds, which will increase the precipitation of strengthening phases. Hence, higher strength can be achieved.

\section{Conclusions}

Under the condition of slow cooling, AA2618 alloy was of complex as-cast microstructures with lots of eutectic compounds including $\mathrm{Al}_{9} \mathrm{FeNi}, \mathrm{Al}_{7}(\mathrm{CuNi})_{5}, \mathrm{Si}, \mathrm{Al}_{2} \mathrm{Cu}$ and $\mathrm{Al}_{2} \mathrm{CuMg}$. The intermetallic compound $\mathrm{Al}{ }_{9} \mathrm{FeNi}$ was very developed with both flower-like and radiated type structures. The radiated type structure extended through several grains.

Phase $\mathrm{Al}_{9} \mathrm{FeNi}$ was the dominant intermetallic compound, which precipitated at the earlier stage of solidification by eutectic reaction $\mathrm{L} \rightarrow \alpha-\mathrm{Al}+\mathrm{Al}{ }_{9} \mathrm{FeNi}$, and grew into radiated type structure. As the alloy continued to solidify and the solid fraction increased, the eutectic reaction was limited within triangle grain boundaries and the intermetallic formed flower-like morphologies.

Increasing cooling rate would suppress the formation of radiated type structures of intermetallic $\mathrm{Al}_{9} \mathrm{FeNi}$. The eutectic cluster of $\mathrm{Al}_{9} \mathrm{FeNi}$ mainly displayed flower-like. The eutectic cellular increased in quantity. 
Under the condition of near-rapid cooling, the as-cast microstructure of the alloy consisted of primary $\alpha$-Al plus metastable intermetallics $\mathrm{Al}{ }_{9} \mathrm{FeNi}$ and $\mathrm{Al}_{2} \mathrm{Cu}$; the equilibrium eutectic compounds were suppressed.

The intermetallics could be refined to a great extent by near-rapid cooling.

\section{Acknowledgments}

The authors are grateful to the Research Foundation of Shenyang Aerospace University for its financial support.

\section{Author Contributions}

All the co-authors of the paper have contributed to the research and writing of the paper. Ming Liu and Lei Luo performed the experiments and analyzed the data; Jijie Wang and Chunzhong Liu contributed to the discussion of the experiments and the paper writing. Yulin Liu directed the research.

\section{Conflicts of Interest}

The authors declare no conflict of interest.

\section{References}

1. Oguocha, I.N.A.; Yannacopoulos, S.; Yan, J. The structure of $\mathrm{Al}_{x} \mathrm{FeNi}$ phase in $\mathrm{Al}-\mathrm{Cu}-\mathrm{Mg}-\mathrm{Fe}-\mathrm{Ni}$ alloy (AA2618). J. Mater. Sci. 1996, 31, 5615-5621.

2. Polmear, I.J.; Couper, M.J. Design and development of an experimental wrought aluminum alloy for use at elevated temperatures. Metall. Trans. A 1988, 19, 1027-1035.

3. Sakthivel, A.; Palaninathan, R.; Velmurugan, R.; Rao, P.R. Production and mechanical properties of SiC particle-reinforced 2618 aluminum alloy composites. J. Mater. Sci. 2008, 43, 7047-7056.

4. Liu, K.; Cao, X.; Chen, X.G. Tensile properties of Al-Cu 206 cast alloys with various iron contents. Metal. Mater. Trans. A 2014, 45, 2498-2507.

5. Özbek, İ. A study on the re-solution heat treatment of AA 2618 aluminum alloy. Mater. Charact. 2007, 58, 312-317.

6. Cavaliere, P. Hot and warm forming of 2618 aluminum alloy. J. Light Met. 2002, 2, 247-252.

7. Seifeddine, S.; Johansson, S.; Svensson, I.L. The influence of cooling rate and manganese content on the $\beta-\mathrm{Al}_{5} \mathrm{FeSi}$ phase formation and mechanical properties of $\mathrm{Al}-\mathrm{Si}$-based alloys. Mater. Sci. Eng. A 2008, 490, 7047-7056.

8. Yu, K.; Li, W.; Li, S.; Zhao, J. Mechanical properties and microstructure of aluminum alloy 2618 with $\mathrm{Al}_{3}(\mathrm{Sc}, \mathrm{Zr})$ phases. Mater. Sci. Eng. A 2004, 368, 88-93.

9. Oguocha, I.N.A.; Yannacopoulos, S. Natural ageing behavior of cast alumina particle-reinforced 2618 aluminum alloy. J. Mater. Sci. 1996, 31, 3145-3151.

10. Wang, J.; Yi, D.; Su, X.; Yin, F. Influence of deformation ageing treatment on microstructure and properties of aluminum alloy 2618. Mater. Charact. 2008, 59, 965-968.

11. Novy, F.; Janecek, M.; Kral, R. Microstructure changes in a 2618 aluminium alloy during ageing and creep. J. Alloys Compd. 2009, 487, 146-151. 
12. Wang, G.J.; Xiong, B.Q.; Zhang, Y.A. Microstructural evolution during creep of a hot extruded 2D70Al-alloy. J. Mater. Sci. 2011, 46, 5090-5096.

13. Liu, K.; Cao, X.; Chen, X.G. Solidification of iron-rich intermetallic phases in $\mathrm{Al}-4.5 \mathrm{Cu}-0.3 \mathrm{Fe}$ cast alloy. Metal. Mater. Trans. A 2011, 42, 2004-2016.

14. Liu, K.; Cao, X.; Chen, X.G. Effect of Mn, Si, and cooling rate on the formation of iron-rich intermetallics in $206 \mathrm{Al}-\mathrm{Cu}$ cast alloys. Met. Mater. Trans. B 2012, 43, 1231-1240.

15. Liu, K.; Cao, X.; Chen, X.G. Formation and phase selection of iron-rich intermetallics in $\mathrm{Al}-4.6 \mathrm{Cu}-0.5 \mathrm{Fe}$ cast alloys. Metal. Mater. Trans. A 2013, 44, 682-695.

16. Liu, Y.L.; Hu, Z.Q.; Zhang, Y.; Shi, C.X. The solidification behavior of 8090 AI-Li alloy. Met. Trans. B 1993, 24, 857-865.

17. Prince, A.; Hari Kumar, K.C. Aluminium-Copper-Nickel. In Light Metal Systems, Part 2, Londolt-Bornstein New Series IV/11A2; Effenberg, G., Ilyenko, S., Eds.; Springer: Berlin/Heidelberg, Germany, 2005; pp. 104-126.

18. Effenberg, G.; Prince, A. Aluminium-Copper-Magnesium. In Light Metal Systems, Part 2, Londolt-Bornstein New Series IV/11A2; Effenberg, G., Ilyenko, S., Eds.; Springer: Berlin/Heidelberg, Germany, 2005; pp. 47-78.

19. Budberg, P.; Prince, A. Aluminium-Iron-Nickel. In Light Metal Systems, Part 2, Londolt-Bornstein New Series IV/11A2; Effenberg, G., Ilyenko, S., Eds.; Springer: Berlin/Heidelberg, Germany, 2005, pp. 329-358.

20. Liu, Y.L.; Zhang, L.; Zhao, Y.H.; Wang, J.J.; Liu, C.Z. The near-rapid solidification behavior of AA1070 aluminum alloy. In Light Metals 2014; Grandfield, J., Ed.; John Wiley \& Sons, Inc.: Hoboken, NJ, USA, 2014; pp. 981-986.

21. Zhang, H.; Gao, R.P. Microstructure and mechanical properties of rapidly solidified $\mathrm{Al}-\mathrm{Cu}-\mathrm{Mg}-\mathrm{Fe}-\mathrm{Ni}$ alloy. Hot Work. Technol. 2005, 5, 11-13. (In Chinese)

(C) 2014 by the authors; licensee MDPI, Basel, Switzerland. This article is an open access article distributed under the terms and conditions of the Creative Commons Attribution license (http://creativecommons.org/licenses/by/4.0/). 